\title{
Rural Community Governance and Cultural Construction in Contemporary China
}

\author{
Na Ning ${ }^{1, a}$ \\ ${ }^{1}$ College of Marxism, Sichuan Agricultural University, Chengdu City, Sichuan Province, 611130, \\ China
}

Keywords: Rural areas; Community governance; Cultural retrieval; Problem; Path

\begin{abstract}
The construction of rural community culture is not only an organic part of rural community public service construction, but also the inherent requirement of building a harmonious society in rural areas. China is in a critical period of transition from traditional society to modern society, and the construction of rural community culture is the core of the community culture construction and development, which has a close relationship with improving the living standards of farmers and the development of rural modernization. Therefore, it is of positive significance to explore the governance of rural communities and cultural construction in contemporary China. Based on the study and practice of the author, this paper firstly analyzed the rural community governance and the significance of cultural construction, and then discussed the rural community governance and cultural construction problems, finally put forward the path of rural community governance and cultural construction.
\end{abstract}

\section{Introduction}

As the core of the construction and development of community culture, the construction of rural community culture is related to the improvement of people's ideological, moral qualities, scientific, cultural qualities and the building of a well-off society with a higher level of benefiting more than one billion people. Therefore, the government must mobilize the enthusiasm of the masses to create cultural activities so that the people's cultural creativity can be fully played. To this end, since the middle of 1980s, the academic community, academic circles and political circles have carried out a targeted study on the construction of rural community culture. The specific meaning and function, main content and characteristics of rural community culture construction in China are systematically analyzed and summarized. They also point out the existing problems and puts forward some suggestions for further research so that to contribute to the theoretical research and practice.

\section{The Significance of Rural Community Governance and Cultural Construction}

First of all, to strengthen the construction of rural community culture is the requirement on farmers. To strengthen the construction of rural community culture can not only provide intellectual support for the development of rural economy, but more importantly arm farmers with the socialist core value system; moreover, to guide farmers with the theoretical system of socialism with Chinese characteristics, to educate farmers with advanced scientific and cultural knowledge and values and to nurture the farmers with positive civilized culture atmosphere are another aims. By strengthening the construction of rural community culture, we can enhance not only the ideological and moral quality, but also the scientific and cultural quality of the farmers. As a result, the majority of the farmers can become the farmers with new ideas and concepts.

Secondly, to strengthen the construction of rural community culture is to meet the needs of the cultural needs of the farmers. In today's society, culture has become an important aspect to reflect the quality of people's lives, and cultural development has become an important symbol of social progress. The level of farmers' cultural quality and the degree of enjoyment of cultural resources have become the important index to measure the quality of the peasants' happiness. Therefore, the 
government should meet the spiritual and cultural needs of the farmers. If the government can not meet the farmers' needs in spiritual and cultural aspects, the backward and even reactionary decadent cultural heritage will be pervasive, resulting in farmers' ideological and moral quality can not be effectively improved, and then restrict the rural economic and social health and harmonious development. Rural community culture has many characters, such as a wide range of radiation, the impact on large area, strong guiding effect, good dissemination effect and so on. By the way of gathering farmers into a large community, the government can strengthen the construction of rural community culture, which further reduces the cost of culture construction, better play the important function of the cultural construction and better improve the cultural quality of farmers ideological and moral qualities so that this become an important carrier of the protecting basic cultural rights and interests of farmers.

Finally, to strengthen the construction of rural community culture can provide new impetus with promoting the rural economy. In the sixth Plenary Session of the 17th CPC Central Committee, it has made a decision to promote the great development and prosperity on culture; the report of the 18th National Congress of the Communist Party of China also poses the development and prosperity of culture at an important position. Accelerating the development of cultural industry has become a new dimension to transform the mode of economic development and achieve the strategic goal of building a moderately prosperous society in an all-round way. At present, the cultural industry is growing rapidly in all parts of the country, and the development of cultural industry is advancing from the city to the countryside. The potential of the rural cultural market is huge, and the demand for cultural consumption is rising. The rural community culture construction based on the development of rural cultural industry can not only better the liberation of a large number of surplus labor, but also increase farmers' income and living standards with accelerating the development of cultural industry and promoting the adjustment and optimization on economic structure so that to accelerate the sound and fast economic and social development.

\section{Problems in Rural Community Governance and Cultural Construction}

Inadequate financial investment on rural community cultural construction. The construction of rural community culture needs a certain amount of funds to support, and one of the fundamental reasons for the backwardness of rural community culture construction in many areas is the lack of financial funds. The first reason is the mechanism of the rural community culture construction, which is not perfect; in the construction of rural community culture, the government has not actively introduced private capital, and they still use governmental financial investment in construction, which can not effectively meet the needs of the broad farmers. The second reason is the construction of rural communities, which still at the initial stage; thus, many rural community infrastructure is not perfect, not to mention cultural construction. The third reason is rural communities, which are not equiping with matchable industrial facilities with slow pace of investment projects so that there is no relevant industry supporting and resulting in lacking financial capital investment.

Lack public cultural infrastructure in rural communities. Through the purchase of the replacement of rural community housing, most of the farmers are transferred from the original village to rural communities, and achieve the dual changes of urbanization and urbanization; Some communities through the way of land transfer realize the modern agricultural scale, mechanization and scientific management, which lead to the reduction on the population of the agricultural labor force employment with many farmers were transferred into workers. With the continuous improvement of income, many farmers began to play poker, mahjong as their main form of entertainment. Many of the villages do not have the corresponding public cultural facilities and cultural activities, and there is no place for entertainment except for playing mahjong; therefore; it is an urgent need to strengthen the construction of rural community culture. If the construction of rural community culture can not keep up its development, the unhealthy atmosphere of rural society will 
grow, and the social stability and economic development in rural areas will be affected.

Rural community culture construction team is weak. The rural community culture construction team is the pillar of the rural cultural construction, and it is responsible for the specific organization of rural cultural activities, the prosperity of the important task of rural cultural undertakings. However, due to the poor rural infrastructure, difficult conditions, inadequate investment and loose personnel management, the current rural cultural construction team is quite weak.

\section{Rural Community Governance and Cultural Construction Path}

Increase investment in rural communities and overally construct the rural community cultural service system. The sixth Plenary Session of the 14th CPC Central Committee pointed out: "the construction of socialist spiritual civilization should have material guarantee; without the necessary material protection, many tasks of the construction of spiritual civilization will be difficult to implement” on Resolution of the Central Committee of the Communist Party of China on Several Important Issues Concerning Strengthening the Building of Socialist Spiritual Civilization. To strengthen the construction of rural community culture is an important guarantee to increase the fund input. It is necessary to explore new ways to innovate the system and work methods, to seek truth from facts, to establish and improve the mechanism of material input and guarantee for the construction of rural community culture and to increase the material input of rural cultural construction. First, to improve the proportion of investment in the construction of rural community culture continuously will ensure that farmers enjoy the fair rights of public cultural products; secondly, attention should be paid to improve the efficiency of fiscal funds utilization, and to establish an effective evaluation mechanism of public cultural input in rural communities as soon as possible. Thirdly, gradually establish a national, social, collective, individual combination led by the government and social aspects of multiple channels so that to raise funds in supplement of investment system; the construction of rural community culture is to ensure adequate funding and to ensure the purchase of all kinds of activities and the necessary equipment. Fourth, the we will actively encourage social forces to contribute to the establishment of public welfare cultural undertakings in rural areas relying on the strength of all parties to build a public cultural service system, which led by government, cooperated by all departments, constructed by the society and participated by the people.

Strengthen the construction of cultural infrastructure in rural communities and build a public cultural service network. Rural cultural infrastructure is not only the material carrier of the farmers' cultural activities, but also an important foundation for the sustainable development of rural cultural undertakings; in addition, it is an important position for spreading socialist spiritual civilization and developing healthy recreational activities. Since most of the rural cultural facilities in rural areas are relatively backward, it is necessary to strengthen the construction of cultural facilities in rural communities from the actual situation in rural areas; to develop county, villages and towns, rural community cultural facilities and cultural venues and the construction of rural public cultural service network must take the government at the county level as the leadership relying on villages and towns, as well as the rural community as the focus with regarding the farmers as the objects.

Rural communities should organize young activities outside the school gathering a series of comprehensive cultural stations, including book-reading, radio and television, publicity and education, theatrical performances, science and technology promotion, science and technology training and sports, etc. Morever, it will establish the cultural bases. The township should be equipped with multi-functional mobile cultural vehicles in order to carry out flexible, diverse and convenient cultural services. In short, the construction of rural community culture is a systematic project, so we should make use of all social forces to set up the cultural infrastructure of rural communities, and accelerate the pace of rural community culture construction. 
Strengthen the construction of rural community cultural talent team and provide a strong organizational guarantee. The communist party of China has put forward in the sixth Plenary Session of the 17th CPC Central Committee: in promoting the great development and prosperity of socialist culture, the team is the foundation and talent is the key. To improve and perfect the system of rural community culture construction is the system and organization guarantee of rural community culture construction. First, the establishment of rural community culture construction professional team, whose work is mainly to understand the spiritual and cultural needs of local farmers and do a good job of related research work in order to promote the healthy development of rural community culture construction. Second, we should strengthen the backbone of the rural community culture construction, and attach importance to the training work. Each region not only has its own cultural characteristics, but also has its own folk talent artist. They come from farmers and serve farmers; they created the most popular form of culture to the people's daily lives, which will be welcomed by the people. Third, the government needs to develop rural community cultural volunteer teams. In the process of the construction of rural community culture, the government should encourage professional cultural workers and other people to join the mass cultural activities, and formed a stable with professional and rural cultural volunteers.

\section{References}

[1] Wang Jianxin. Thinking on the Construction of Rural Community Culture [J]. Law and Society, 2013, (07): 208-209+234.

[2] Wang Lina. Literature Review of Rural Community Culture Construction [J]. Journal of Shenyang Institute of Engineering (Social Science Edition), 2012, (04): 467-470.

[3] Li Yanrong, Cao Fengchun. Thinking on Strengthening the Construction of Rural Community Culture [J]. New West (Theoretical Edition), 2012, (03): 13-14.

[4] Cai Liangzhi, Zhang Hua. Analysis of the Path of Rural Community Culture Construction [J]. Journal of the Party School of the CPC Sichuan Provincial Committee, 2011, (04): 74-75.

[5] Li Zengyuan. Rural Community Construction: Governance Transformation and Community Building [J]. Southeast Academic, 2009, (03): 26-31.

[6] Wang Hongxing. Discussion on the Construction of Rural Community Culture in China [J]. Modern Business and Industry, 2009, (05): 48-49.

[7] Zhang Guifang. Analysis of the construction of rural Community culture in the Transformation period [J]. Journal of Lanzhou, 2004 (05): 213-214. 